\title{
A New Species of Afrotropical Ants in the Genus Bothroponera (Hymenoptera: Formicidae: Ponerinae)
}

\author{
Abdulmeneem M. A. Joma ${ }^{1,2}$ and William P. Mackay ${ }^{2}$ \\ ${ }^{1}$ Department of Zoology, Faculty of Sciences, The University of Sebha, P.O. Box 18758, Sebha, Libya \\ ${ }^{2}$ Department of Biological Sciences, Ecology and Evolutionary Biology Program, The University of Texas at El Paso, \\ 500 West University Avenue, El Paso, TX 79968, USA
}

Correspondence should be addressed to Abdulmeneem M. A. Joma; alnoure69@yahoo.com

Received 3 April 2013; Accepted 24 June 2013

Academic Editor: Abraham Hefetz

Copyright (c) 2013 A. M. A. Joma and W. P. Mackay. This is an open access article distributed under the Creative Commons Attribution License, which permits unrestricted use, distribution, and reproduction in any medium, provided the original work is properly cited.

\begin{abstract}
We describe a new species of Afrotropical Bothroponera from Whittlesea City, Eastern Cape Province, South Africa. This species is unique among the African Bothroponera as it is the only species with a horizontal propodeal spiracle. It is also the largest species of African Bothroponera (total length 14.80-15.65). The clypeus lacks a medial longitudinal carina, the head is subquadrate, the sculpture is mostly foveolate, and the second gastral segment nearly lacks sculpturing. We compare the new species to the similar B. cavernosa and B. cavernosa var. montivaga. We also compare the new species to all of the other 10 taxa that belong to the cavernosa complex. A key to the cavernosa complex species of the Afrotropical Bothroponera is provided along with diagnosis, comparison, distribution, habitat, biology, and etymology for the new species.
\end{abstract}

\section{Introduction}

1.1. Ants of Africa and Their Importance. Ants are generally considered a remarkable model for the study of population dynamics and ecosystem structure and function, especially in tropical, subtropical, and biodiversity hotspot areas, because of the ecological roles of these organisms in ecosystems. Ant species are considered keystone species in several terrestrial ecosystems and are unique in that they can interact biologically and ecologically with other organisms and display huge positive and negative effects on ecosystem [1-6]. They play almost all of the roles of symbiotic relationships with other organisms. Biologists study ant species for several reasons: they are easy to handle, able to survive in various habitats, adapt to extreme environments, and are small in size. Afrotropical regions are especially rich with ant species, where they disperse seeds in the Fynbos biome in South Africa $[3,7,8]$. Ant species play a central role in maintaining the vegetation at the appropriate density. Afrotropical ants are very important in optimal ecosystem management, such as Oecophylla longinoda in South Africa [9].
1.2. Current Estimations of African Ant Diversity. Studies are still insufficient to estimate the actual number of species of African ants, which includes about 16 subfamilies and 83 to 154 genera $[2,10]$. The largest subfamilies are Myrmicinae with about 6983 species, Formicinae with about 3709 species, and Ponerinae with about 1250 species. Studies on the biodiversity of African ants demonstrate that these important organisms have a high species richness and great biodiversity in African ecosystems. Afrotropical ant genera have been sampled in several projects. Belshaw and Bolton [11] collected 47 genera in Ghana; Lindsey and Skinner [12] recorded 17 genera in Tussen die Riviere Game Reserve, Free State in South Africa; Parr and Chown [13] collected 16 genera from the central Satara area of the Kruger National Park, South Africa; Fisher [14] collected 56 genera on Monts Doudou in Southwestern Gabon; Yanoviak et al. [15] collected 14 genera in Gamba, Gabon; Braschler et al. [16] collected 35 genera in South Africa; Schoeman and Foord [17] collected 29 genera at the Marakele National Park, Limpopo province, South Africa; Hita Garcia et al. [18] recorded 52 genera from Kakamega Forest, Western Kenya. Robertson [2] listed 83 genera of 
Afrotropical ants. Some genera (44) have received modern taxonomic revision, while 39 genera including Pachycondyla have not been revised. By simple calculations, based on the previous studies and $[10,19]$, the approximate number of African ant genera (excluding Malagasy genera) is about 126154. The number will increase soon as a result of the current active work on revisions of Afrotropical ants.

1.3. Subfamily Ponerinae and Tribe Ponerini Characters. Bothroponera belongs to the subfamily Ponerinae, which includes three tribes, Platythyreini, Ponerini, and Thaumatomyrmecini [20]. The worker of the subfamily Ponerinae can be recognized by several characters [20], including a welldeveloped sting, the toruli are completely fused to the frontal lobes, which are greatly narrowed posteriorly, and the palpal segments are reduced in length. The promesonotal suture is present and flexible with the pronotum and mesonotum capable of movement relative to each other. The metapleural gland orifice is simple. The clypeus is well developed. The petiole is present, the postpetiole is not separated from the gaster [21]. The petiole represents the second abdominal segment, the postpetiole is the third abdominal segment (first gastral segment), and the rest of abdominal segments are gastral segments 4-7. The Ponerinae can often be recognized by a stridulatory organ on the dorsal surface of the second acrotergite $[20,21]$. The petiole is without tergosternal fusion [20]. The Ponerinae is considered to be a heterogeneous assemblage of ants [6]. The worker of the tribe Ponerini also has special characteristics such as the petiole has a slender articulation on the ventral side of the first gastral segment, palpal joints are reduced in number, and the frontal carinae converge posteriorly [21]. The clypeus has an anterior medial raised area and is narrowed from the sides of the head. The frontal lobes cover the base of the insertion of the scapes. The helcium projects from very low down on the anterior face of third abdominal segment, the latter with a high vertical anterior face above the helcium. This tribe is considered as a paraphyletic group based on apomorphic characteristics [20].

1.4. Genus Pachycondyla. Since 1858, when Smith described the genus Pachycondyla [22], myrmecologists have continued to add new subgenera, and recently this genus and the proposed generic synonyms have reached a state of unclear taxonomic identity. This genus includes 18 subgenera, which in the future will probably be separated into more than 18 genera, Bothroponera being one of them. The taxonomic level of Pachycondyla is still under extensive study in that it could be a paraphyletic or even a polyphyletic assemblage. The morphological characters of these ants are heterogeneous; there is no apomorphic character that defines the genus [23], which suggests several separate genera within Pachycondyla $[23,24]$. Genetic studies [25] revealed that the karyotypes of Pachycondyla species are extremely variable; most karyotypes are with large chromosome numbers, (more than 11 chromosomes), while others have smaller chromosome numbers (fewer than 11 chromosomes), and the morphological characters of the chromosomes are variable. Since there are independent patterns of karyotype evolution in the
Pachycondyla genome, there are several genera that should be distinct from Pachycondyla [25].

1.5. Genus Bothroponera. The genus Bothroponera was described by Mayr in 1862 [26]. The majority of myrmecologists, such as von Dalla Torre, Bingham, Ashmead, W. M. Wheeler, Bernard, Taylor et al., G. C. Wheeler and J. Wheeler, Taylor, and Dlussky and Fedoseeva [27-35], agreed that Bothroponera is a separate genus; however, Bothroponera and Pachycondyla are closely related to each other. The characteristics that are used to distinguish the genus Bothroponera in this paper are based on descriptions of the entire group of African Bothroponera species ( 40$)$. The genus is characterized by the narrowed, convex, and medially raised clypeus. The mandibles are triangular or narrowed with 6-9 teeth. The frontal lobes are rounded or semioval, divided by a well-developed frontal furrow. The pronotum of the worker lacks any evidence of a carina or shelf. The mesonotum is completely fused with the propodeum, and the notopropodeal suture is completely absent. The petiole is thick with a developed ventral process. The mesopleuron is not divided by an anapleural suture and is well separated from the metapleuron by the mesometapleural suture.

1.6. Global Distribution of the Genus Bothroponera. The genus Bothroponera in Africa occurs mainly in tropical and subtropical areas. The biogeographical information shows that the genus Bothroponera is present only in the Afrotropical, Oriental, and Australian Regions. There are about 92 species of Bothroponera distributed worldwide, but Bothroponera is absent from the Palearctic, Nearctic, and Neotropical Regions. The Bothroponera species are distributed as the following: Madagascar 9 taxa (Bothroponera cambouei, $B$. comorensis, B. masoala, B. perroti, B. perroti admista, B. planicornis, B. tavaratra, B. vazimba, and B. wasmannii revised as Pachycondyla [36]; Australia 16 taxa (Bothroponera excavata var. acuticostata, B. astuta, B. barbata, B. denticulata, B. dubitata, B. excavata, $B$. piliventris var. intermedia, $B$. sublevis subsp. kurandensis, B. mayri, B. sublevis var. murina, $B$. piliventris, $B$. porcata, $B$. piliventris subsp. regularis, $B$. sublaevis $\mathrm{r}$. reticulata, $B$. sublaevis var. rubicunda, and $B$. sublaevis) [33]; New Guinea has five species (Bothroponera incisa, $B$. obesa, $B$. simillima, $B$. striata, and $B$. verecund $a$ ); and India has eight taxa (Bothroponera sulcata var. fossulata, B. bispinosa, B. henryi, B. leeuwenhoeki, B. rufipes, B. sulcata, B. sulcata var. sulcatotesserinoda, and B. tesseronoda). In Asia there are about 15 taxa distributed as the following: Philippines two species (Bothroponera glabripes and B. williamsi); Indonesia four species ( $B$. insularis, $B$. solitaria, $B$. unicolor, and $B$. vermiculata); Borneo four taxa (B. sandakana, B. insularis var. brevior, B. tridentata, and B. tridentata $\mathrm{r}$. debilior); Myanmar one species (B. rubiginosa); Sri Lanka one taxon (B. rufipes subsp. ceylonensis); West Malaysia one taxon (Bothroponera tridentata var. exasperans); Singapore one species (B. havilandi); and Vietnam one species (Bothroponera annamita) $[10,37]$.

In Africa there are about 40 species of Bothroponera distributed as the following: Guinea one species, Sierra 
Leone one species, Ghana one species, Cameroun four species, Democratic Republic of Congo four species, Congo Brazzaville four species, Angola one species, Ethiopia four species, Kenya three species, Tanzania one species, Malawi one species, Mozambique one species, Zimbabwe two species, and South Africa ten species. They are clustered in three major areas in African continent according to their complexes: eastern countries are the favorite habitat for the crassa complex, western countries are the habitat for the talpa complex, and southern countries are the main ecosystems for the cavernosa complex. The African taxa in the cavernosa complex include Bothroponera berthoudi Forel, 1901, B. cariosa Emery, 1895, B. cavernosa (Roger, 1860), B. cavernosa var. montivaga Arnold, 1947, B. granosa (Roger, 1860), B. laevissima Arnold, 1915, B. laevissima var. aspera Arnold, 1962, B. pumicosa (Roger, 1860), B. strigulosa Emery, 1895, and B. variolosa Arnold, 1947.

In this paper, the morphological description of a new species of African Bothroponera is provided. The illustrations of the head (full face) and the lateral view of the body are included. The lateral view shows the horizontal propodeal spiracle on the lateropropodeum. A taxonomic key to the species complexes of the Afrotropical Bothroponera as well as taxonomic key of the cavernosa complex species is provided along with diagnosis, comparison, distributional information, habitat, biology, and etymology of the new species.

\section{Material and Methods}

2.1. Specimens Collections. The two worker specimens of the new species were obtained from the Museum of Comparative Zoology, Harvard University, Cambridge, MA, USA (MCZC). The male and queen are unknown. The other museums that provided us with the African Bothroponera specimens are the following:

Naturhistorisches Museum (NHMB), Basel, Switzerland.

Muséum d'Histoire Naturelle (MHNG), Geneva, Switzerland.

Iziko South African Museum (SAM).

Dr. William Mackay's collection (CWEM) the University of Texas at El Paso.

British Natural History Museum (BMNH), London. Museum für Naturkunde (ZMHU), Berlin, Germany. Museum Nationale d'Histoire Naturelle (MNHN), Paris, France.

Museo Civico di Storia Naturale (MCSN), Genova, Italy.

American Museum of Natural History (AMNH), New York.

Los Angeles County Museum of Natural History (LACM), California.

2.2. Measurement Abbreviations. The specimens were examined with a Zeiss binocular microscope with an ocular micrometer. All measurements are in millimeters.
Head length (HL), in full face view, the maximum length of the head excluding the mandibles, from the midpoint of the anterior clypeal margin to the midpoint of the posterior margin of the head.

Head width (HW), in full face view, the maximum width of the head from the extreme side of head to the other extreme side excluding the eyes.

Mandible length (ML), the distance from the mandible's base to the apex of the apical tooth.

Eye length (EL), the maximum diameter of the eye as seen from the side.

Eye Width (EW), the maximum distance of the eye from the anterior edge to the posterior edge as seen from the side.

Scape length (SL), the maximum length of the scape from the proximal to the distal extremes, excluding the basal constriction.

Funiculus length (FL), the measurement of the distal 11 segments of the antenna including the club and all of the funicular segments.

Weber length (WL), the length in lateral view, from the anterior edge of the pronotum to the end of posterior margin of the propodeal lobes.

Petiole length (PL), in lateral view, the maximum distance of the petiole from the anterior face to the posterior side excluding the helcium.

Petiole width (PW), in dorsal view, the maximum side to side thickness of the petiole, generally at the posterior edge since it has the largest width.

Petiole height $(\mathrm{PH})$, in lateral view, the maximum length from the lower point of the sternopetiolar process, excluding the petiolar teeth, to the highest point at the apex of the petiolar node.

The following indices are used:

$$
\begin{aligned}
& \text { cephalic index }(\mathrm{CI}), \mathrm{HW} / \mathrm{HL} \times 100 \text {, } \\
& \text { ocular index }(\mathrm{OI}), \mathrm{EL} / \mathrm{HW} \times 100, \\
& \text { mandible index }(\mathrm{MandI}), \mathrm{ML} / \mathrm{HL} \times 100 \text {, } \\
& \text { scape index }(\mathrm{SI}), \mathrm{SL} / \mathrm{HW} \times 100, \\
& \text { petiole index }(\mathrm{PetI}), \mathrm{PW} / \mathrm{PL} \times 100 \text {. }
\end{aligned}
$$

2.3. Further Measurements and Descriptions. In each specimen, we measured the hair length, the total body length, the malar space length (from lower edge of the eye to the base of the mandible), and the length of the side of the head from the upper margin of the eye to the highest point of the posterior lateral corner of the head (side view). There are other characters that are taken into account including the shape of the head, eyes (large or small), pronotum, mesopleuron, propodeum, petiole, and postpetiole. The shape of the pronotal shoulder, lower margin of the pronotum, basalar sclerite, and propodeal spiracle are important. The entire body color including the antennae, clypeus, mandibles, and legs was described as well. 
2.4. Nomenclatural Acts. The new name contained in this paper is available under the International Code of Zoological Nomenclature (ICZN). This work and the nomenclatural acts it contains have been registered in ZooBank. Zoobank life science identifier (LSID) for this publication is urn:lsid:zoobank.org:pub:29432EB5-CF41-4FF6-BFC9F63DD64C502E. The LSID registration and any associated information can be viewed in a web browser by adding the LSID to the prefix "http://zoobank.org/."

\section{Results and Discussion}

The following are the diagnosis of the worker, description, and measurements of the new species, Bothroponera umgodikulula $n \mathrm{sp}$. (Figures 1 and 2).

3.1. Diagnosis of the Worker. The main distinguishable characters of B. umgodikulula are the lack of sculpture on the tergum of fourth abdominal segment (second gastral segment), which is mostly smooth and glossy, and the horizontal propodeal spiracle. The worker is also characterized by the large total length, which is $14.80-15.65 \mathrm{~mm}$. The head is subquadrate (CI 95.00-95.16). The clypeus is convex, "v" shaped, and covered with striae, except for the medial area. The anterior medial area is raised and coarsely punctate on the sides, and smooth and glossy in the middle, but an actual carina is absent. The mandibles are triangular, shorter than the head length (MandI 50.00-54.83), smooth and glossy with scattered elongated coarse punctures and about 7 teeth. The scape reaches or extends slightly past the posterior border of the head (SI 81.35-82.45). The compound eyes are relatively large (OI 15.25-15.78). The lower margins of the frontal lobes are smooth; the upper part is punctate. The maximal frontal lobe width is $1.10-1.20 \mathrm{~mm}$. The head is subquadrate and coarsely foveolate. The length of the malar space on the side of the head is $(0.65-0.70 \mathrm{~mm})$; the length from the upper edge of the eye to the edge of posterior lobe is $1.35-1.50 \mathrm{~mm}$.

The pronotum, dorsum of the mesonotum, and dorsum of the propodeum are coarsely foveolate and rough. The dorsum of the petiole and postpetiole are coarsely foveolae and punctate. The mesopleuron and lateropropodeum are coarsely grooved and covered with striae, foveolae, and punctures. The propodeal spiracle is unusual in being nearly horizontal. The pronotal shoulder is rounded. The antennae, legs, and posterior edge of each gastral tergite are shiny. The petiole is rounded and slightly narrowed anteriorly, while it is slightly concave posteriorly (PetI 115.38-125.92).

The entire head, pronotum, mesonotum, propodeum, petiole, and postpetiole are covered with short (0.03$0.10 \mathrm{~mm}$ ) fine golden hairs. The ventral side of the postpetiole and fourth-seventh gastral segments are covered with relatively long $(0.20-0.25 \mathrm{~mm})$ golden suberect hairs. The hairs on underside of the head range from 0.25 to $0.50 \mathrm{~mm}$ in length.

The head, pronotum, mesonotum, mesopleuron, propodeum, petiole, postpetiole, and entire gaster are black. The legs, antennae, mandibles are red. The clypeus is dark brown.

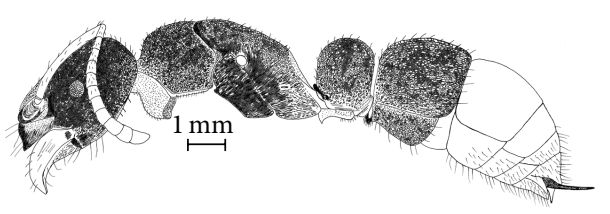

FIgURE 1: Side view of the holotype worker of B. umgodikulula.

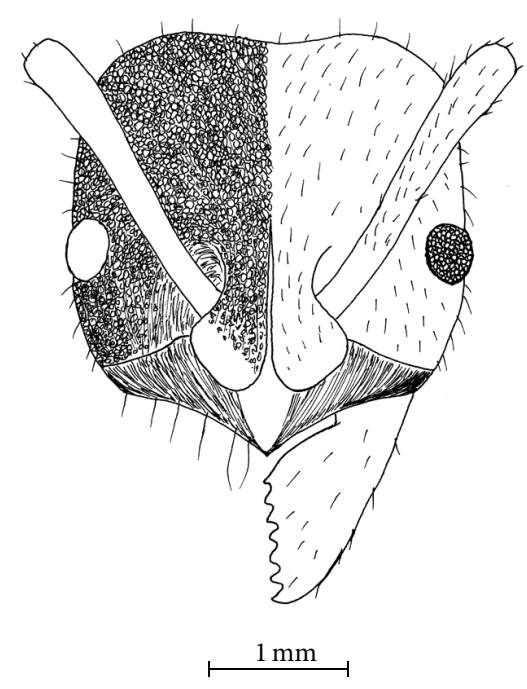

FIGURE 2: Full face view of the holotype worker of B. umgodikulula.

\subsection{Description}

3.2.1. Worker Measurements and Indices $(n=2)$. HL 3.003.10, HW 2.85-2.95, ML 1.50-1.70, EW 0.40-0.45, EL 0.45, SL 2.35-2.40, FL 3.65-3.75, WL 4.20, WPL 5.00-5.50, PL $1.30-1.35$, PW 1.50-1.70, PH 1.75-1.80, CI 95.00-95.16, OI 15.78-15.25, MandI 50.00-54.83, SI 82.45-81.35, and PetI $115.38-125.92$.

3.2.2. Worker Characteristics. Head excluding mandibles subquadrate with rounded sides; mandibles smooth, glossy with scattered elongated coarse punctures and fine longitudinal striolae, with about 7 teeth, mandible shorter than head length; clypeus covered with longitudinal striae (except medial area), medial area raised, without forming carina, disc smooth and glossy, sides coarsely punctate; eyes relatively large; scape reaches or extends slightly past posterior border of head; lower lateral margins of frontal lobes smooth, upper part punctate; dorsum of head mostly foveolate; pronotum, mesonotum, propodeum rough, and coarsely foveolate; mesopleuron, lateropropodeum covered with foveolae, with punctures, striae, and coarse grooves; pronotal shoulder rounded; basalar sclerite nearly oval; propodeal spiracle nearly horizontal; antennae, legs shiny; petiole rounded, slightly narrowed anteriorly, slightly concave posteriorly; dorsum and sides of petiole, postpetiole (first gastral segment) coarsely foveolate, punctate; second gastral segment to tip of gaster mostly smooth, punctate, with weak markings of foveolae; entire head, pronotum, mesonotum, propodeum, 
petiole, and postpetiole covered with short golden erect hairs; hairs on underside of head long; head, pronotum, mesonotum, mesopleuron, propodeum, petiole, postpetiole, entire gaster black; legs, antennae, and mandibles red; clypeus reddish brown.

3.3. Comparison. The new species is a member of the African cavernosa species complex of the genus Bothroponera, in which the metatibial gland on the ventral tibial hind leg is absent and the clypeus is convex with " $v$ " shaped anterior margin. Bothroponera umgodikulula is easily recognized by the horizontal propodeal spiracle (parallel to the posteropropodeum in the remainder of the Bothroponera species). In addition, the smooth and glossy 4th abdominal segment (second gastral segment) of $B$. umgodikulula is different from the sculptured segments of the similar $B$. cavernos $a$ and $B$. cavernosa var. montivaga. The 4 th abdominal segment of $B$. cavernosa is rough, moderately shiny with few scattered hairs and fine poorly defined striae, while that of B. cavernosa var. montivaga is somewhat smooth and moderately shiny (less so than B. umgodikulula) with a few scattered punctures. The other taxa that can be confused with B. umgodikulula are $B$. laevissima and B. laevissima var. aspera because they both have smooth and glossy 4th abdominal segments, but it is easy to recognize them by the body surface. Most surfaces of $B$. umgodikulula are coarsely foveolate whereas they are smooth and shiny in B. laevissima and with a few punctures in B. laevissima var. aspera. The new species B. umgodikulula is also characterized by the larger body size (total length $14.80-15.65 \mathrm{~mm}$ ) compared to B. cavernosa $(11.90 \mathrm{~mm})$ and B. cavernosa var. montivaga $(12.20-12.65 \mathrm{~mm})$. In fact, the new species is the largest species among the other cavernosa complex species (B. granosa $13.75-14.50 \mathrm{~mm}, B$. variolosa $12.15-12.75 \mathrm{~mm}, B$. strigulosa $12.20 \mathrm{~mm}$, B. laevissima $11.80-13.00 \mathrm{~mm}$, B. laevissima var. aspera $11.70-12.70 \mathrm{~mm}$, B. pumicosa $11.00-11.65 \mathrm{~mm}, B$. cariosa $11.50 \mathrm{~mm}$, and $B$. berthoudi $9.60 \mathrm{~mm}$ ). Bothroponera cavernosa var. montivaga and $B$. cavernosa share most of the characteristics with the new species except the propodeal spiracle, which is obliquely vertical in $B$. cavernosa var. montivaga and $B$. cavernosa, while it is horizontal in B. umgodikulula. The new species $B$. umgodikulula is the only species among the cavernosa complex species that has a horizontal propodeal spiracle. The anterior medial margin of the clypeus is "v" shaped in $B$. umgodikulula similarly to that of $B$. granosa, $B$. cavernosa, $B$. cavernosa var. montivaga, and B. laevissima var. aspera. Conversely, the anterior medial margin of the clypeus is "u" shaped in B. cariosa, B. strigulosa, B. pumicosa, B. laevissima, $B$. berthoudi, and B. variolosa. The clypeus has a sharp carina on the raised area in B. granosa; it is partially carinated in B. cavernosa and B. cavernosa var. montivaga, and the lower parts are smooth. The anterior medial raised area of B. umgodikulula is completely smooth (lacking the carina), and shiny, but sculptured and punctate on sides of the medial raised area. The scape of $B$. umgodikulula reaches or slightly exceeds the posterior lateral corner of the head, while it is slightly shorter in B. cavernosa var. montivaga and slightly longer in B. cavernosa.
3.4. Material Examined. Type series, South Africa: Eastern Cape, Bulhoek, Klaver-Clanw., Bulhoek at $32^{\circ} 10^{\prime} 0^{\prime \prime} \mathrm{S}$; $26^{\circ} 49^{\prime} 0^{\prime \prime} \mathrm{E}$, Mus. Expd. October 1950, (2 w, holotype (MCZC) and paratype (SAM) no. C005835) Bothroponera cavernosa Roger, 1860, F. W. G., SAM-HYM SAM.

3.5. Distribution. The species is known only from Bulhoek (Whittlesea), Eastern Cape, South Africa.

3.6. Biology and Habitat. The new species (Bothroponera umgodikulula) is collected from the Bulhoek area in South Africa. Bulhoek is the former name of Whittlesea in the Eastern Province of South Africa. The average elevation of the area is about $1,060 \mathrm{~m}$. The main vegetation in Whittlesea is grassland $[38,39]$. The Eastern Cape Province includes about six different types of biomes: fynbos, savanna, thicket, grassland, nama karoo, and forest biomes. The area is characterized by different habitats that results in high biodiversity. In fact, most of the cavernosa complex species were found in South Africa especially in the Cape Provinces. There are at least 24 taxa that belong to Pachycondyla and Bothroponera collected from South Africa, including Bothroponera berthoudi; B. cavernosa; $B$. cavernosa var. montivaga; $B$. granosa; $B$. kruegeri; $B$. laevissima var. aspera; $B$. pumicosa; $B$. strigulosa; $B$. variolosa; Pachycondyla aenigmatica; $P$. caffraria; $P$. elisae rotundata; P. fossigera; P. hartwigi; P. havilandi; P. havilandi fochi; $P$. havilandi godfreyi; $P$. havilandi marleyi; $P$. hottentota; $P$. peringueyi; $P$. peringueyi saldanhae; $P$. tarsata; $P$. wroughtonii and $P$. wroughtonii crudelis. This high diversity is not only because of the extensive studies that have been conducted in South Africa, but it is also because of the numerous habitats and ecosystems that characterize the country.

3.7. Etymology. The name of the new species of African Bothroponera "umgodikulula" comes from isiZulu, one of the major South African languages. The word "umgodi" means hole, and "kulula" means level, to express that this species has a hole for respiration that is situated horizontally on the lateropropodeum.

\subsection{Key to the Afrotropical Bothroponera Complexes}

(1) Metatibial gland present; scape extends at least first funicular segment past posterior lateral corner of head; lower margin of anterior medial area of clypeus convex, straight, or slightly concave; eyes range from small to large (EW 0.05-0.45, EL 0.05-0.70) ... crassa complex.

- Metatibial gland absent; scape shorter, barely reaches posterior lateral corner of head, or extends past less than length of first funicular segment ...2.

(2) Anterior margin of anterior medial area of clypeus convex, "u" or "v" shaped; eyes relatively large (EW and EL $0.30-0.45 \mathrm{~mm}$ ) ... cavernosa complex.

- Anterior margin of clypeus straight, or slightly concave, or slightly convex but not "v" or "u" shaped; eyes 
relatively small (EW and EL $0.15-0.40 \mathrm{~mm}$ ) ... talpa complex.

\subsection{Preliminary Key to the Afrotropical Cavernosa Complex Species of the Genus Bothroponera}

(1) Scapes relatively short, barely reaching, or slightly exceeding posterior lateral corner of head, (SI 78.0087.17); head subquadrate or suborbicular (CI 78.18100); clypeus convex, anterior border "v" or " $\mathrm{u}$ " shaped, and sharp medial longitudinal carina present on clypeus, or partially carinated, or lacking carina; mandibles with 7-8 teeth without striae (MI 48.2759.61); body sculptured with foveolae or punctae; fourth abdominal segment (second gastral segment) smooth, slightly rough, or sculptured; hairs length ranges from 0.03 to $0.55 \mathrm{~mm}$... 2 .

- Scapes slightly longer, extending past posterior lateral corner of head (SI 77.77); head suborbicular, cephalic index 90.00; clypeus convex, anterior border "v" shaped with partial longitudinal carina on the upper part; mandibles with 7 teeth, covered with fine striae (MI 48.33); body strongly sculptured by foveolae; fourth abdominal segment slightly rough with fine hairs scattered on dorsum; hairs lengths ranges from $0.03-0.20 \mathrm{~mm}$... cavernosa.

(2) Hairs on scape short, $1 / 2-1 / 3$ greatest diameter of scape $(0.07-0.17 \mathrm{~mm})$; hairs on posterior tibia $0.15-$ $0.30 \mathrm{~mm}$, with few to many suberect to erect hairs throughout length; few hairs on mandibles (fewer than $0.20 \mathrm{~mm}$ ) with about 7 teeth, at least in part glossy, shiny, and possibly with coarse punctures or with few fine striae, mandibular index (48.27-59.61); anterior border of clypeus " $v$ " or "u" shaped, lacking carina, or partially carinated; fourth abdominal segment smooth, or slightly rough, or sculptured ... 3 .

- Hairs on scape long, at least as long as the greatest diameter of scape $(0.50-0.55 \mathrm{~mm})$; hairs on posterior tibia about $0.30-0.35 \mathrm{~mm}$; mandibles hairy $(\sim 0.20 \mathrm{~mm})$ with about 8 teeth, mandibular index 50.90-52.00; anterior border of clypeus "u" shaped, anterior medial area raised to form partial carina on upper part; fourth abdominal segment sculptured, covered with shallow foveolae ... pumicosa.

(3) Entire body smooth, shiny; ocular index 14.00-15.09 ... laevissima.

- Entire body coarsely sculptured with foveolae or punctae, ocular index $15.25-21.42 \ldots 4$.

(4) Propodeal spiracle nearly horizontal; anterior border of clypeus "v" shaped with longitudinal raised medial area, but lacking carina; head subquadrate (CI 95.0095.16); fourth abdominal segment smooth, glossy ... umgodikulula.

- Propodeal spiracle nearly vertical; anterior border of clypeus "v" or "u" shaped, sharp carina present on clypeus, partially carinated, or lacking carina; head subquadrate or suborbicular (CI 82.75-100); fourth abdominal segment slightly rough or sculptured ...5.

(5) Body with sparse punctures, moderately shiny, black; anterior border of clypeus " $v$ " shaped, lacking carina; head suborbicular (CI 90.19-90.90); fourth abdominal segment smooth shiny ... laevissima var. aspera.

- Body sculptured foveolae or punctate, black, brownish, or brownish dark, brown or reddish brown appendages; anterior border of clypeus "u" or "v" shaped, carina present, lacking carina, or partially carinated; head suborbicular or subquadrate; fourth abdominal segment slightly roughened or sculptured ...6.

(6) Anterior border of clypeus "u" shaped with or without carina; scape reaching or slightly surpassing posterior lateral corner of head ... 7.

- Anterior border of clypeus "v" shaped with at least partial carina; scape not reaching posterior lateral corner of head ... 8 .

(7) Mandible with scattered coarse punctures that unite to some degree, forming poorly defined rugulae, mandible shorter than head length (MI 59.61); fine carina present on anterior medial raised area of clypeus; posterior border of petiolar node (seen from above) with depression medially; fourth abdominal segment sculptured, covered with shallow foveolae... cariosa.

- Mandible with scattered isolated punctures that do not unite, completely smooth and glossy between punctures with little evidence of striae or rugulae, mandible shorter than head length (MI 48.27-56.45); anterior medial raised area of clypeus with or without sharp carina or lacking carina; posterior border of petiolar node with little evidence of depression; fourth abdominal segment (second gastral segment) slightly roughened or sculptured ...9.

(8) Eyes relatively smaller (OI 16.66-18.18); clypeus with sharp longitudinal carina on anterior border; petiolar index (116.66-123.07); fourth abdominal segment (second gastral segment) sculptured, covered with shallow foveolae, striae ... granosa.

- Eyes relatively larger (OI 18.36-18.75); partial carina present on anterior border of clypeus; petiolar index (130.00); fourth abdominal segment smooth with few scattered punctures ... cavernosa var. montivaga.

(9) Erect hairs on scape short (most less than $0.10 \mathrm{~mm}$ in length, few up to $0.20 \mathrm{~mm}$ ), scape not reaching posterior lateral corner of head (SI 78.57); erect golden hairs on entire dorsum of body $(0.07-0.13 \mathrm{~mm}$, a few up to $0.16 \mathrm{~mm})$, hairs on petiole $(0.15-0.18 \mathrm{~mm})$; clypeus forming sharp medial carina on the medial raised area; mandibular index (54.00) ... strigulosa.

- Erect hairs on scape short $(0.07-0.10 \mathrm{~mm})$, scape reaching or nearly reaching posterior lateral corner of head (SI 82.22-87.17); moderately short erect golden 
hairs on mesosoma (most over $0.06 \mathrm{~mm}$, few over $0.25 \mathrm{~mm}$ in length), but longer (most over $0.25 \mathrm{~mm}$ ) suberect hairs on petiole and postpetiole $(0.25 \mathrm{~mm})$; clypeal medial area not forming carina (smooth and rounded); mandibular index $(55.10-55.55) \ldots$ variolosa and berthoudi.

\section{Acknowledgments}

The authors would like to thank the curators and museums who provided Afrotropical ant specimens including Dr. Claire Villemant (MNHN), Dr. Bernhard Merz (MHNG), Drs. Stefan Cover, Philip Perkins, Jack Boyle, and Charles Whittemore Farnum (MCZC), Drs. Frank Koch and Viola Richter (ZMHU), Drs. Roberto Poggi, Giuliano Doria, and Maria Tavano (MCSN), Drs. Isabelle Zürcher-Pfander, and Daniel Burckhardt (NHMB), Drs. Gavin Broad and Suzanne Ryder (BMNH), Drs. James Carpenter and Christine LeBeau (AMNH), Drs. Weiping Xie and Laura McGover (LACM), and Dr. Dawn Larsen (SAM). Special thanks are due to Dr. Gary Alpert who offered to take photos of the Bothroponera species and allowed the authors lodging during the study period at the Museum of Comparative Zoology. Dr. Alain Dejean provided several publications on African ants; Dr. Hamish Robertson provided his ant publication website; Dr. Brigitte Braschler offered useful information about African ant richness and biodiversity, and Dr. Nigel Worden, from the University of Cape Town, offered historical information about South Africa. Thanks are also due to Dr. Barry Bolton, who suggested useful comments for ant character descriptions and identifications. An anonymous reviewer made important suggestions to improve the paper, for which the authors are grateful. The authors also thank Dr. Robert Kirken, Chairman of the Department of Biological Sciences of the University of Texas at El Paso, who facilitated procedures to borrow specimens from SAM, Dr. Elizabeth Walsh, Ph.D. advisor and the doctoral committee members Dr. Carl Lieb, Dr. Eli Greenbaum, Dr. Michael Moody, and Dr. Mahesh Narayan, as well as Dr. Shawn Dash and Dr. Jerry Johnson, for assistance and useful suggestions. This research was supported by Grant no. G12MD007592 from the National Institutes on Minority Health and Health Disparities (NIMHD), a component of the National Institutes of Health (NIH), and also supported by the Libyan Ministry of Higher Education, Libyan-North American Scholarship Program, and Canadian Bureau for International Education. This paper fulfills one of the requirements for the Doctor of Philosophy degree in Ecology and Evolutionary Biology at the University of Texas at El Paso.

\section{References}

[1] B. Hölldobler and E. O. Wilson, The Ants, The Belknap Press of Harvard University Press, Cambridge, Mass, USA, 1990.

[2] H. G. Robertson, "Afrotropical ants (Hymenoptera: Formicidae): taxonomic progress and estimation of species richness," Journal of Hymenoptera Research, vol. 9, no. 1, pp. 71-84, 2000.
[3] K. French and R. E. Major, "Effect of an exotic Acacia (Fabaceae) on ant assemblages in South African fynbos," Austral Ecology, vol. 26, no. 4, pp. 303-310, 2001.

[4] D. Grimaldi and M. S. Engel, Evolution of the Insects, Cambridge University Press, Cambridge, Mass, USA, 2005.

[5] R. M. Pringle, D. F. Doak, A. K. Brody, R. Jocqué, and T. M. Palmer, "Spatial pattern enhances ecosystem functioning in an African savanna," PLoS Biology, vol. 8, no. 5, Article ID e1000377, 2010.

[6] P. S. Ward, “Taxonomy, phylogenetics, and evolution," in Ant Ecology, L. Lori, C. L. Parr, and K. L. Abbott, Eds., chapter 1, Oxford University Press, New York, NY, USA, 2010.

[7] N. Farwig and D. G. Berens, "Imagine a world without seed dispersers: a review of threats, consequences and future directions," Basic and Applied Ecology, vol. 13, no. 2, pp. 109-115, 2012.

[8] M. A. Rodriguez-Cabal, K. L. Stuble, B. Guénard, R. R. Dunn, and N. J. Sanders, "Disruption of ant-seed dispersal mutualisms by the invasive Asian needle ant (Pachycondyla chinensis)," Biological Invasions, vol. 14, no. 3, pp. 557-565, 2012.

[9] M. J. Way and K. C. Khoo, "Role of ants in pest management," Annual Review of Entomology, vol. 37, pp. 479-503, 1992.

[10] http://www.antweb.org/.

[11] R. Belshaw and B. Bolton, "A survey of the leaf litter ant fauna of Ghana, West Africa (Hymenoptera: Formicidae)," Journal of Hymenoptera Research, vol. 3, pp. 5-16, 1994.

[12] P. A. Lindsey and J. D. Skinner, "Ant composition and activity patterns as determined by pitfall trapping and other methods in three habitats in the semi-arid Karoo," Journal of Arid Environments, vol. 48, no. 4, pp. 551-568, 2001.

[13] C. T. Parr and S. L. Chown, "Inventory and bioindicator sampling: testing pitfall and winkler methods with ants in a South African savanna," Journal of Insect Conservation, vol. 5, no. 1, pp. 27-36, 2001.

[14] B. L. Fisher, "Diversity patterns of ants (Hymenoptera: Formicidae) along an elevational gradient on Monts Doudou in southwestern Gabon. In: Monts Doudou, Gabon: A Floral and Faunal Inventory with Reference to Elevational Variation," California Academy of Sciences, vol. 28, pp. 269-286, 2004.

[15] S. P. Yanoviak, B. L. Fisher, and A. Alonso, "Arboreal ant diversity (Hymenoptera: Formicidae) in a central African forest," African Journal of Ecology, vol. 46, no. 1, pp. 60-66, 2008.

[16] B. Braschler, S. L. Chown, and K. J. Gaston, “The Fynbos and Succulent Karoo biomes do not have exceptional local ant richness," PLoS ONE, vol. 7, no. 3, Article ID e31463, 2012.

[17] C. S. Schoeman and S. H. Foord, "A checklist of epigaeic ants (Hymenoptera: Formicidae) from the Marakele National Park, Limpopo, South Africa," Koedoe, vol. 54, no. 1, pp. 1-7, 2012.

[18] F. Hita Garcia, G. Fischer, M. K. Peters, R. R. Snelling, and J. W. Wägele, "A preliminary checklist of the ants (Hymenoptera: Formicidae) of Kakamega Forest (Kenya)," Journal of East African Natural History, vol. 98, pp. 147-165, 2009.

[19] http://www.webarchive.org.uk/wayback/archive/ 20100617220041/http://antbase.org/ants/africa/contents.htm.

[20] B. Bolton, "Synopsis and classification of Formicidae," Memoirs of the American Entomological Institute, vol. 71, pp. 1-370, 2003.

[21] W. M. Wheeler, Ants: Their Structure, Development and Behavior, Columbia University Press, New York, NY, USA, 1910.

[22] F. Smith, Catalogue of Hymenopterous Insects in the Collection of the British Museum, Part VI. Formicidae, British Museum, London, UK, 1858. 
[23] W. P. Mackay and E. E. Mackay, The Systematics and Biology of the New World Ants of the Genus Pachycondyla (Hymenoptera: Formicidae), The Edwin Mellen Press, Lewiston, NY, USA, 2010.

[24] W. P. Mackay and E. E. Mackay, "A new species of the ant genus Pachycondyla F. Smith, 1858 from Ecuador (Hymenoptera: Formicidae)," Myrmecologische Nachrichten, vol. 8, pp. 49-51, 2006.

[25] C. D. S. F. Mariano, S. D. G. Pompolo, J. G. Silva, and J. H. C. Delabie, "Contribution of cytogenetics to the debate on the paraphyly of Pachycondyla spp. (Hymenoptera, Formicidae, Ponerinae)," Psyche, vol. 2012, Article ID 973897, 9 pages, 2012.

[26] G. Mayr, "Myrmecologische Studien," Verhandlungen der Kaiserlich-Koniglichen Zoologisch-Botanischen Gesellschaft in Wien, vol. 12, pp. 649-776, 1862.

[27] K. W. von Dalla Torre, Catalogus Hymenopterorum hucusque descriptorum systematicus et synonymicus, Formicidae (Heterogyna), vol. 7, W. Engelmann, Leipzig, Germany, 1893.

[28] C. T. Bingham, The Fauna of British India, Including Ceylon and Burma. Hymenoptera, Ants and Cuckoo-Wasps, vol. 2, Taylor and Francis, London, UK, 1903.

[29] W. H. Ashmead, "A skeleton of a new arrangement of the families, subfamilies, tribes and genera of the ants, or the superfamily Formicoidea," The Canadian Entomologist, vol. 37, pp. 381-384, 1905.

[30] W. M. Wheeler, "Ants of the American Museum Congo expedition, A contribution to the myrmecology of Africa, IX. A synonymic list of the ants of the Malagasy region," Bulletin of the American Museum of Natural History, vol. 45, pp. 1005-1055, 1922.

[31] F. Bernard, "Les fourmis du Tassili des Ajjer. Pp. 121-250 in: Bernard, F., (ed.) Mission scientifique au Tassili des Ajjer (1949), Recherches zoologiques et médicales, Paris," P. Lechevalier, vol. I, p. 302, 1953.

[32] R. W. Taylor, D. R. Brown, and J. C. Cardale, Zoological Catalogue of Australia, vol. 2 of Hymenoptera: Formicoidea, Vespoidea and Sphecoidea, Canberra, Australia, 1985.

[33] G. C. Wheeler and J. Wheeler, "A simplified conspectus of the Formicidae," Transactions of the American Entomological Society, vol. 111, pp. 255-264, 1985.

[34] R. W. Taylor, "A checklist of the ants of Australia, New Caledonia and New Zealand," CSIRO Division of Entomology Report, vol. 41, pp. 1-92, 1987.

[35] G. M. Dlussky and E. B. Fedoseeva, "Origin and early stages of evolution in ants," in Cretaceous Biocenotic Crisis and Insect Evolution, A. G. Ponomarenko, Ed., pp. 70-144, Nauka, Moscow, Russia, 1988.

[36] J. C. Rakotonirina and B. L. Fisher, "Revision of the Pachycondyla wasmannii-group (Hymenoptera: Formicidae) from the Malagasy region," Zootaxa, vol. 3609, no. 2, pp. 101-141, 2013.

[37] B. Bolton, G. Alpert, P. S. Ward, and P. Naskrecki, Bolton's Catalogue of Ants of the World 1758-2005, Harvard University Press, 2007.

[38] http://www.mbendi.com/a_sndmsg/place_view.asp?pid=9678.

[39] http://en.wikipedia.org/wiki/Whittlesea. 

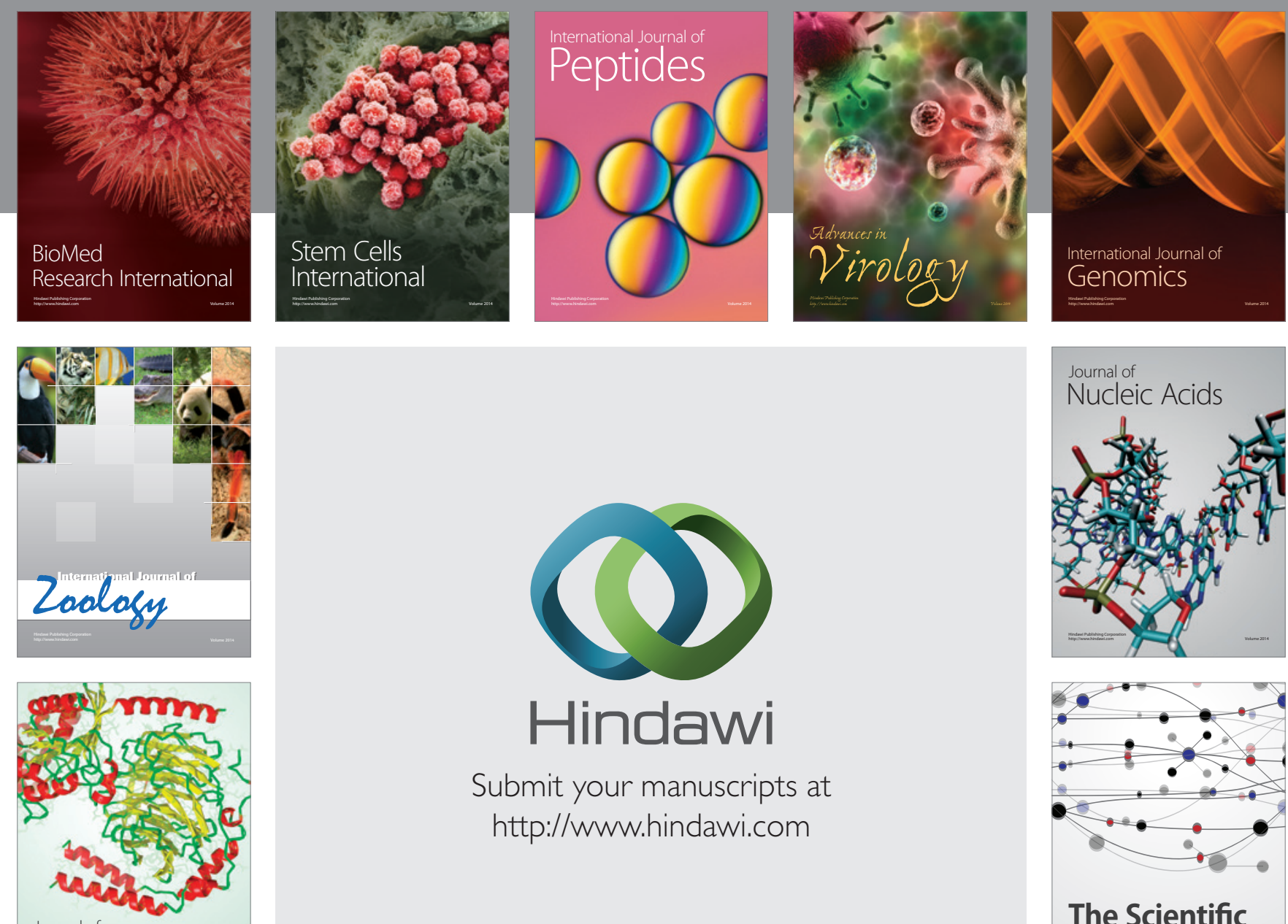

Submit your manuscripts at

http://www.hindawi.com

Journal of
Signal Transduction
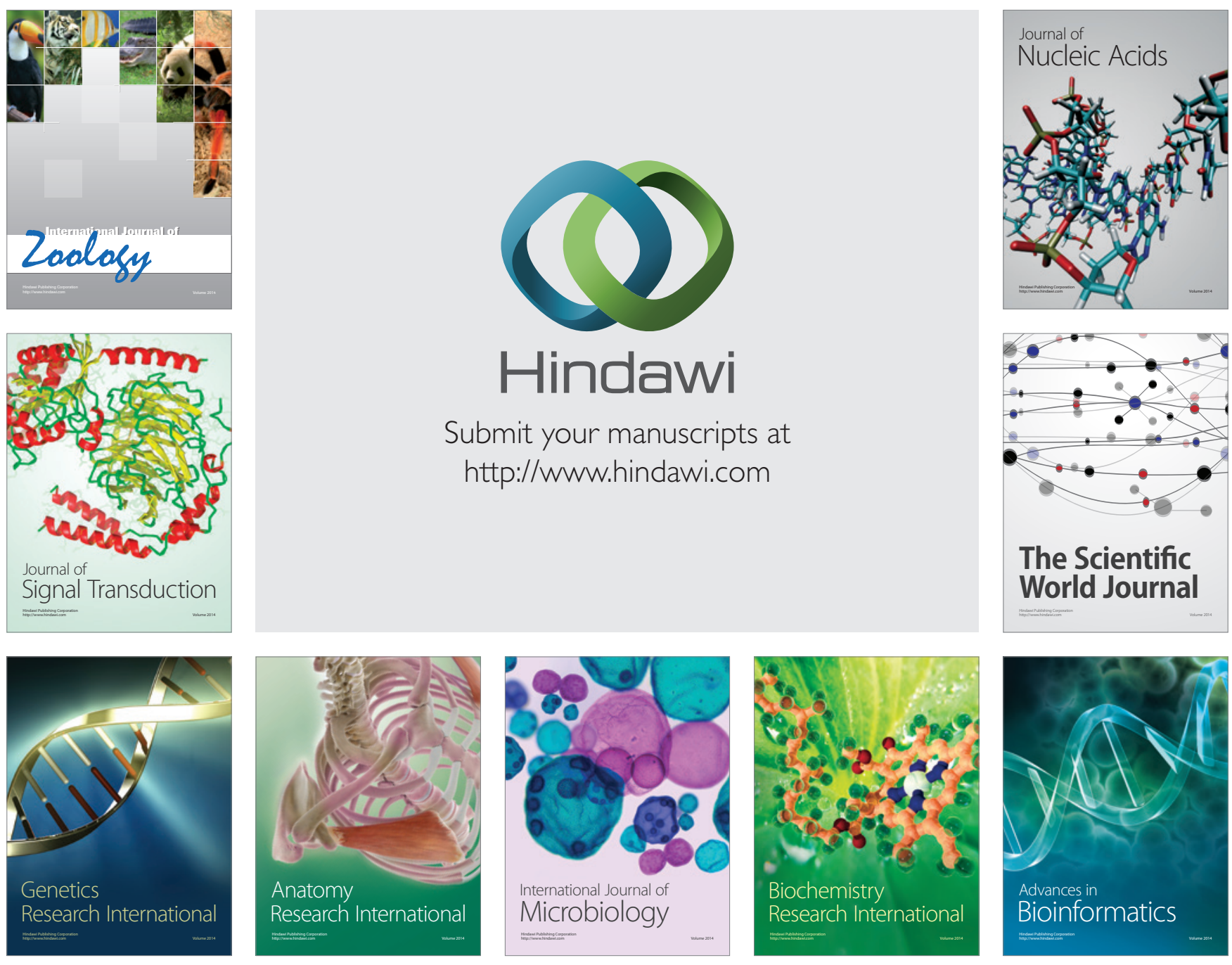

The Scientific World Journal
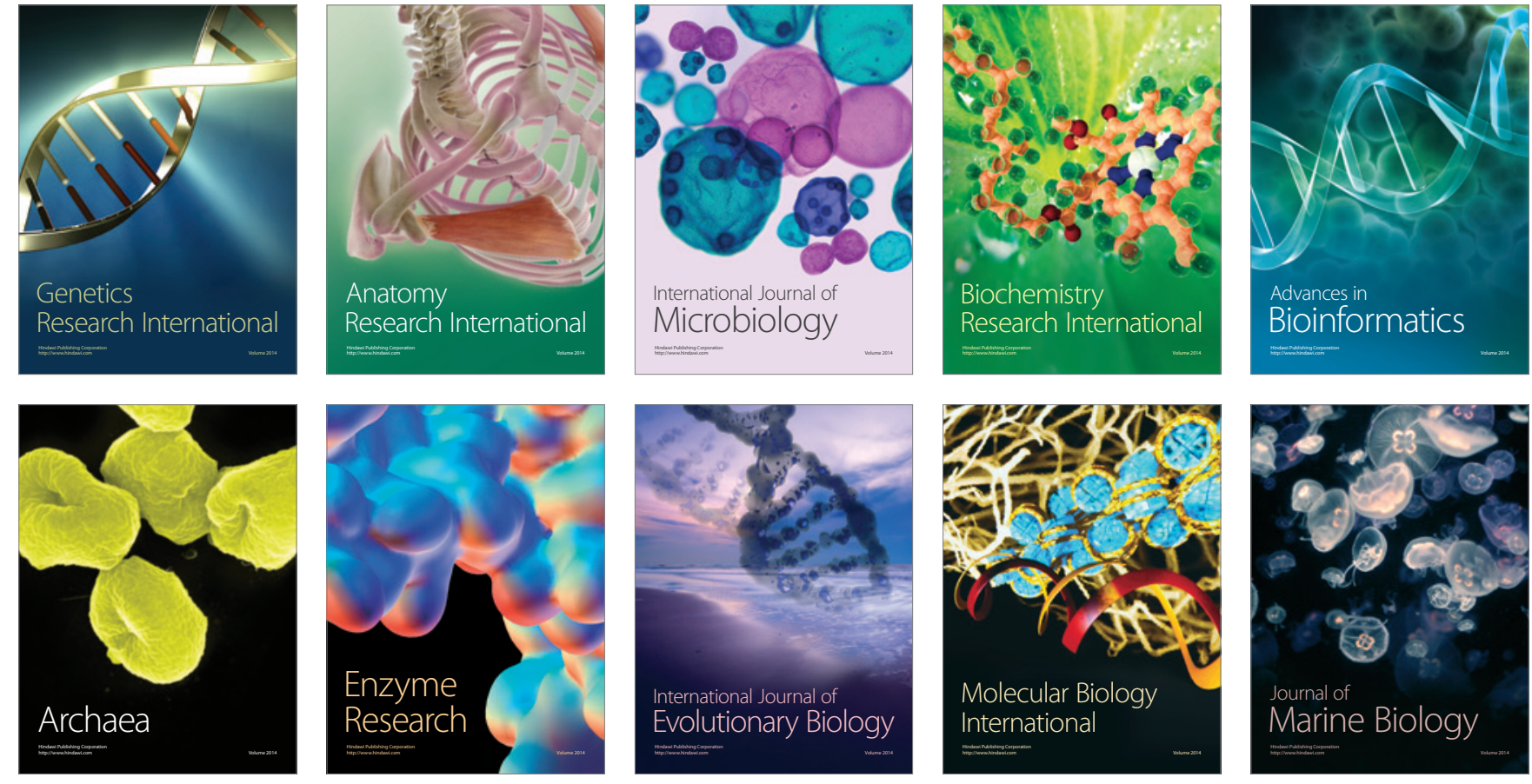